\title{
How do international faculty at Japanese universities view their integration?
}

\author{
Lilan Chen ${ }^{1}$ \\ Accepted: 6 December 2021 / Published online: 7 January 2022 \\ (c) The Author(s), under exclusive licence to Springer Nature B.V. 2022
}

\begin{abstract}
The purpose of the study is to explore how international faculty at Japanese universities view their integration. An exploratory study of semi-structural interviews with 40 fulltime international faculty hired in Japanese universities with various backgrounds was conducted. The key findings indicate that international faculty perceived their integration as a beneficial longstanding two-way process of acquiring equality, developing engagement, and forming a feeling of attachment towards Japan. Meanwhile, their actual practices towards their integration appear to be diverse, which can be summarized into three broad categories, namely, preventive, occasional, and promotional. The study suggests a disjunction between international faculty's attitudes and their actual practices towards their integration, which is influenced by the overall host environment from a macro perspective, work role from a meso perspective, and personal intention, origin of country, and previous experience in Japan from a micro perspective. Theoretical and practical implications drawn from the key findings are provided to not only better understand the integration of international faculty at Japanese universities, but also to better serve and support them in practice.
\end{abstract}

Keywords Integration · International faculty · Japanese universities · Qualitative

\section{Introduction}

With the development of globalization and the internationalization of higher education (HE), the international mobility of highly skilled talent has been an intense concern for policymakers and researchers in recent decades. International faculty have been considered as one of those groups (Wang et al., 2019). Experience of staying abroad has contributed to their career development, and to the knowledge innovation, and the academic diversity of their hosts (Teichler, 2017). Significant efforts have been made by the Japanese government to hire international faculty, leading to their increase from $1.17 \%(1,285)$ in 1983 to $4.71 \%(8,850)$ in 2019 (MEXT, 2020). Despite rapid expansion, empirical evidence suggests that international faculty at Japanese universities perceive themselves as "tokenized symbols" of internationalization (Brotherhood et al., 2020). Therefore, scholars' attention

Lilan Chen

lilanchen@hiroshima-u.ac.jp

1 Research Institute for Higher Education, Hiroshima University, Higashihiroshima, Japan 
has been directed to not only their recruitment but also their integration into Japan, which is one of the most critical challenges for both international faculty and the efforts towards systematic organizational reform (Oishi, 2020).

Despite its perceived value, questions about the nature and shape of integration and international faculty's attitudes towards their integration remain. In Japan, despite the rapid expansion of international faculty, most of the previous studies remain mainly engaged with their general outlook (e.g., Huang, 2018a, 2018b; Huang \& Chen, 2021; Huang \& Daizen, 2020), and scholarly focuses have lagged behind. Therefore, further investigation in this regard is needed, especially from the perspectives of international faculty themselves, since the practicalities and difficulties of integration are largely experienced by them. When it comes to the themes concerning the integration of international faculty, such as if they are integrated or if their integration is necessary, international faculty's personal perceptions should be central.

In order to fill this gap, the study explores how international faculty at Japanese universities view their integration. A qualitative approach of semi-structural interviews with 40 full-time international faculty hired in Japanese universities was applied. The study first provides a brief literature review, followed by an explanation of methodology. The third part is concerned with interview results. Finally, the study summarizes and discusses major findings, presenting implications for policymakers, university administrators, and researchers, as well as pointing out limitations.

\section{Literature review}

\section{Discourses about integration}

The term integration has been widely used as a form of incorporation, which can be investigated from three main theoretical perspectives: assimilationism, multiculturism, and structuralism (Alba \& Nee, 1997). Assimilation implies immigrants adapt to their hosts. In HE settings, similar terms have been used. For example, "cross-cultural transition" is employed to describe strategies to cope with marginalization (McClure, 2007). Kim (2018) employs "academic socialization" to illustrate the "sensitivity towards the local culture and the interaction-related features." However, the use of these terminologies merely emphasizes the one-way adaptation of international faculty, which is contradictory to the prevailing arguments emphasizing bi-directional mutual exchange (Gheorghiu \& Stephens, 2016).

Regarding multiculturalism, it is considered desirable due to its fundamental denial of the assimilation theory and emphasis on the presence of immigrants. Studies on international faculty's integration from this perspective are often associated with interculturality, diversity, and internationalization (Kim, 2009, 2016; Shin \& Gress, 2018), and interactions with locals are highlighted. For example, Jiang et al. (2010) use "academic acculturation" to describe the process whereby international faculty become a part of a group and integrate with its members. However, this has been criticized due to its overemphasis on the cultural and ethnic aspects and its failure to identify how immigrants "construct their own acculturation and assimilation" (Zhou, 1997: 982).

As for structuralism, it underscores the objective dimensions of social structures, such as employment and housing (e.g., Ager \& Strang, 2008). But this theoretical framework 
can hardly explain the tokenization of international faculty who are hired as highly skilled professionals in Japan.

In summary, it appears that integration is heavily contextualized due to differences stemming from historical and social-cultural aspects. And the three main theoretical frameworks reviewed above are not applicable to the case of international faculty in Japan. The preceding conditions inform a necessity to explore integration of international faculty in the specific context of Japan.

\section{Research on integration of international faculty}

Scholarly interests in the integration of international faculty are generally placed on their practical adaptation experience to integrate into their host countries. Often, they address international faculty's constraints of integration, which fall mainly into two broad categories, namely, work-related and social-cultural issues. Regarding work-related issues, existing evidence suggests that imbalances in power and resources make international faculty unlikely to integrate into their host institutions, since they are more commonly confined to disadvantageous working conditions, such as low-ranking positions, lower salaries, enlarged job responsibilities, reduced autonomy and freedom (Corley \& Sabharwal, 2007; Selmer \& Lauring, 2011; van der Wende, 2015). In addition, the tension caused by the fact that the recruitment of international faculty is associated with the demoting of native-born colleagues who were hired in the same positions leads to perceived stress and rejection of international faculty by their native-born colleagues (Collins, 2008). Moreover, a significant influence from teacher-student relationships has also been noted (Jonasson et al., 2017; Wilkins \& Neri, 2019).

Factors in social-cultural aspects are also among the most researched themes concerning integration, which affect both work performance and satisfaction of international faculty (Wilkins \& Neri, 2019). The first issue often addressed is the language barrier, which impacts their academic performance, acceptance by their native-born colleagues, and communication with students (Gahungu, 2011; Yudkevich et al., 2017). In addition, cultural distance was found to negatively impact the interaction and relationship establishment with natives (Jonasson et al., 2017). Likewise, Froese (2012) indicates that both cultural and language dissimilarities are significant for international faculty's integration professionally and socially. Furthermore, some illustrate international faculty's inability to socialize with local colleagues, which results in their perceptions of isolation (Froese, 2010; Gress $\&$ Shin, 2020). Cultural differences can lead to international faculty's disconnection from local society, their lack of participation in social activities, affecting their interpersonal and professional developments, which in turn impedes their integration.

In Japan's context, existing literature in migration and intercultural studies has constantly demonstrated immigrants' negative experiences, such as their marginalization (CAPOBIANCO, P., 2017), biases (Rogers et al., 2020), and frustration (O'Keefe, 2017). Regarding the integration of international faculty, despite a more accommodating university environment compared to industrial settings (O'Neill, 2014), it is fraught with numerous challenges, such as distinctive work roles and limited professional opportunities (Huang, 2018a; McNeill, 2007; Yonezawa et al., 2014). For example, some argued that they have been undertaking the duties that the "regular" Japanese faculty cannot do or do not wish to perform (Huang, 2018a). Some even perceived themselves as a show window to externally visualize the internationalization of Japanese universities, especially those who have visible foreign appearances (Brotherhood et al., 2020). 
Previous studies have consistently taken the integration of international faculty solely as person-environment fit from organizational perspectives, in other words, to what extent international faculty co-responded to their hosts. Yet the questions remain about the nature and shape of their integration, whether this person-environment fit can be taken as integration, and if it's necessary. In addition, the substantial body of previous studies in Japan has focused primarily on the work dimension of international faculty, other aspects, such as their psychological state, which has been identified as a significant factor impacting their retention (O'Meara, 2014), has been largely omitted from previous discussions. Therefore, it is necessary to investigate integration from the subjective perspectives of international faculty themselves.

\section{Methodology}

\section{Conceptual framework and research questions}

The Theories of Action proposed by Argyris and Schön (1974) was recruited in the study, which comprises two theoretical frameworks: espoused theories and theories-in-use. Espoused theories represent the theories that individuals behave in a given situation, which were constituted by their norms and assumptions. Whereas, theories-in-use refers to individuals' practical actions that produce outcomes (Argyris \& Schön, 1974). Additionally, according to Argyris and Schön (1974), Espoused theories are constructed on a cognitive basis, conditioned by various factors, eventually form theories-in-use. Thus, the espoused theories may not always be compatible with theories-in-use (Argyris et al., 1987). The adoption of this framework in the study can be explained by its distinctive contribution of "understanding human action" (Argyris, 1976:20), which largely enables the investigation of international faculty's views regarding their integration in Japan, specifically their attitudes and practices. Additionally, it also helps to identify the influential individual and organizational factors of the consistency/inconsistency between their cognitive attitudes and actual practices.

Based on the literature review and the Theories of Action, the study seeks to answer the following research questions:

1. What are international faculty's attitudes towards their integration in Japan?

2. How do international faculty integrate into Japan in practice?

\section{Methods}

In answering these research questions, semi-structural interviews with 40 full-time international faculty hired by Japanese universities were conducted. The main interview question was "How do you view the integration of international faculty in practice?." Follow-up questions were also asked to better explore their perceptions and attitudes. Due to the COVID-19 pandemic, except for 8 face-to-face interviews, the remaining interviews were conducted online from July to November of 2020, using platforms such as Zoom, Skype, and Wechat. English, Chinese, and Japanese were used as the main languages of these interviews. A majority of the interviews were recorded and transcribed professionally for further analysis, except for two interviews. To ensure the accuracy of 
the information of the interviews, transcripts have been reviewed and approved by some of the participants, including the two participants without recording. The duration of the interviews varied between $40 \mathrm{~min}$ to $2 \mathrm{~h}$. Out of ethical considerations, serial numbers were used to ensure the confidentiality of the participants.

Regarding the analytic process, a dual strategy of inductive coding and deductive exploration based on the Theories of Action has been employed in the study. The interviews were analyzed through a three-stage procedure. Firstly, all debriefing transcripts were imported into Nvivo 12 in their original languages and coded by the participants' words that emerged originally from the transcripts or special terms which are close to their own words. Secondly, sub-themes were developed through analyzing the coded nodes of the quotations to provide broader patterns. 12 sub-themes were created, such as same treatment as Japanese, favorable environment, relatedness with Japan. In the last stage, the sub-themes were aggregated into more specific themes to better identify the key views of international faculty towards their integration in Japan. For example, the sub-themes of favorable environment and relatedness with Japan have been conceptualized into the theme Engagement, implying the condition or state of being involved.

\section{Population and sampling}

The study applies the main criteria from previous studies (Huang, 2018a, 2018b), identifying international faculty as a full-time employee at a Japanese university who reported his/her nationality as a non-Japan country and was educated at primary and secondary schools outside of Japan.

In order to ensure sufficient variation of the participants, the study took their institutional and individual attributes, such as nationality, gender, the type and location of their affiliations, into consideration. The participants were recruited mainly via three methods. First is the maximum variation purposive sample: the respondents who agreed to be interviewed from Huang's $(2018 \mathrm{a}, 2018 \mathrm{~b})$ national survey $(N=20)$. Formal invitation letters were sent out to the potential participants according to the information they gave in the questionnaire. Second is the criterion sampling: those who were invited from various universities $(N=15)$. Interview requests were sent based on the information on the homepages of their affiliations to increase the number of samples. The third is snowballing sampling: eligible participants were introduced by the participants from the former two groups $(N=5)$. Their institutional and individual attributes were considered accurately before the interviews. The final sample is shown in Table 1.

\section{Interview results}

Drawing on the narratives of participants, the key findings are analyzed subsequently in alignment with the Theories of Action Framework and the research questions. This section first presents international faculty's espoused theories of attitudes towards integration (understanding and intentions), followed by their theories-in-use (actual practices). The main themes were illustrated in Fig. 1. 
Table 1 The outline of the participants

\begin{tabular}{|c|c|c|c|c|c|c|}
\hline NO & Affiliation & Area & Nationality & Position & Educational & Discipline \\
\hline $\mathrm{F} 1$ & National & Chugoku/Shikoku & Iran & A. Prof & degree obtained & Engineering \\
\hline $\mathrm{F} 2$ & National & Chugoku/Shikoku & Bolivia & Ass. Prof & in Japan & Economy \\
\hline F3 & National & Chugoku/Shikoku & India & Ass. Prof & Yes & Physics \\
\hline $\mathrm{F} 4$ & National & Chugoku/Shikoku & Vietnam & Ass. Prof & No & Engineering \\
\hline F5 & Local & Touhoku & Russia & A. Prof & No & Computer science \\
\hline F6 & National & Chugoku/Shikoku & Korea & Ass. Prof & Yes & Education \\
\hline F7 & National & Kyushu/Okinawa & Canada & A. Prof & No & Linguistics \\
\hline F8 & Private & Kinki & China & A. Prof & Yes & Marketing \\
\hline F9 & Private & Kyushu/Okinawa & UK & A. Prof & No & Education \\
\hline F10 & National & Chugoku/Shikoku & Iran & Ass. Prof & Yes & Environment \\
\hline F11 & Private & Kinki & China & Lecture & No & Literature \\
\hline $\mathrm{F} 12$ & Private & Kantou & US & Prof & No & Literature \\
\hline F13 & Local & Kyushu/Okinawa & US & A. Prof & Yes & English \\
\hline F14 & National & Chugoku/Shikoku & $\mathbf{U K}$ & A. Prof & No & Linguistics \\
\hline $\mathrm{F} 15$ & Private & Kantou & Australia & Prof & No & Political Science \\
\hline F16 & Local & Touhoku & UK & A. Prof & No & Education \\
\hline $\mathrm{F} 17$ & Private & Kantou & Ireland & Lecture & No & Computer science \\
\hline F18 & Private & Kantou & German & Prof & No & History \\
\hline F19 & National & Chugoku/Shikoku & Thailand & A. Prof & No & Agriculture \\
\hline $\mathrm{F} 20$ & Private & Kinki & $\mathbf{U K}$ & Prof & No & Literature \\
\hline $\mathrm{F} 21$ & National & Chubu & Ireland & Prof./Rep & Yes & Psychology \\
\hline $\mathrm{F} 22$ & Private & Kinki & US & A. Prof & No & English \\
\hline F23 & National & Kinki & New zealand & Prof & No & Biogeography \\
\hline $\mathrm{F} 24$ & Local & Chubu & US & A. Prof & No & Linguistics \\
\hline F25 & Private & Kyushu/Okinawa & US & Lecture & No & Linguistics \\
\hline F26 & Private & Kantou & $\mathbf{U K}$ & Prof & No & Linguistics \\
\hline F27 & National & Chugoku/Shikoku & US & Ass. Prof & No & Psychology \\
\hline F28 & National & Chubu & China & A. Prof & No & Film Studies \\
\hline F29 & National & Hokkaido & China & Ass. Prof & Yes & Engineering \\
\hline F30 & Local & Chugoku/Shikoku & US & Prof & No & Linguistics \\
\hline F31 & Local & Hokkaido & German & Prof./Dean & Yes & Chemistry \\
\hline F32 & National & Kantou & China & Ass. Prof & No & Anthropology \\
\hline F33 & Private & Hokkaido & UK & A. Prof & No & Education \\
\hline F34 & Private & Hokkaido & Brazile & Lecture & Yes & English \\
\hline F35 & National & Kinki & Mexico & Lecture & No & Chemistry \\
\hline F36 & National & Hokkaido & Srilanka & A. Prof & No & Chemistry \\
\hline F37 & National & Kantou & UK + Poland & Ass. Prof & Yes & Economy \\
\hline F38 & Private & Kyushu/Okinawa & US & Lecture & Yes & Music \\
\hline F39 & National & Touhoku & Brazile & A. Prof & No & Engineering \\
\hline F40 & National & Chugoku/Shikoku & Korea & A. Prof & No & Engineering \\
\hline
\end{tabular}




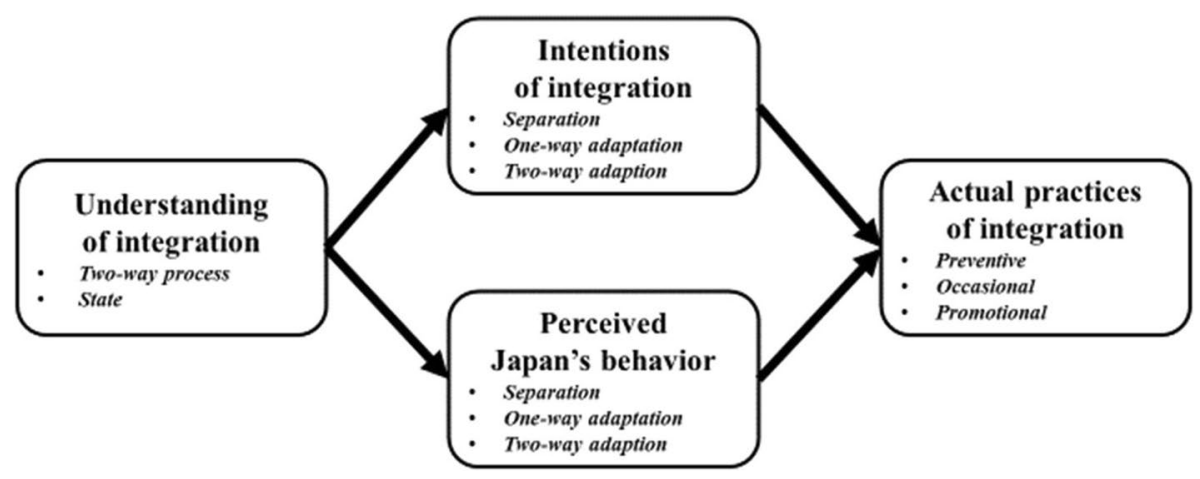

Fig. 1 Themes of international faculty's views towards their integration

\section{Attitudes towards integration}

Despite the vagueness of the term, most participants used concrete examples to demonstrate their abstract ideas and intangible views towards their integration. These specific perceptions and mind states equated with their attitudes toward integration.

\section{Understanding of integration}

Drawing on the interview content, the data analysis suggests that the majority of the participants regarded their integration as positive and valuable, being beneficial in various aspects, including their professional development, character building, intercultural competence enrichment, and mental health. As asserted below:

I think, in any society, you should try to integrate into that society. It's certainly important for your career growth, and also for your mental health. Otherwise you would have numerous difficulties (F1).

I think integrating into a different country is very helpful for personal growth... there are a lot of people who have different cultural backgrounds and values...you will be more open-minded by accepting other people's opinions (F8).

In Japanese, they use Kukiwoyomu (read the atmosphere). So, this is what I'm learning right now. This is beneficial, I will know more about people (F19).

I think it helped me to become more relaxed, more open-minded, or understanding of people...try to understand why people are doing this and why things are like this (F34).

\subsection{Integration as a process}

As for their understanding of integration, many participants believed that it is a process in which both international faculty and Japan are involved. Among those participants, some emphasized that international faculty should attempt to follow Japanese culture and tradition since they were hired under the assumption that they would respect Japan. 
If we are here on the Japanese side, we have to make a very big adjustment...that means understanding the culture and the human interactions and the ways of discourse of your hosts (F7).

In contrast, many participants denied this by asserting that it is the utilization of their specific different knowledge and skills that can contribute to internationalization. Therefore, instead of changing to become more Japanese, those so-called heterogeneities of international faculty should be maintained.

I think it is necessary to show my special personality as a Chinese teacher...it is more appropriate to achieve the value of being a foreign teacher (F11).

We have our own specific functions...the students who interact with me can get some interactions they couldn't get from a Japanese professor because I'm different. I give them Nanka Shogeki (somehow stimulation) (F31).

Likewise, the majority of the participants $(\mathrm{N}=32)$ suggest that the prospect for successful integration should be created by a two-way process in which the mutual adaptation of both international faculty and Japan should be involved.

Integration should be we work and integrate to Japanese culture and styles, and Japan also reflects us. So, it is kind of mutual reaction between environment and us (F4). Integration is to become part of the group. So, I think there are two conditions. One, you want to join the group, and two, the group wants to allow you to join (F16).

\subsection{Integration as a state}

Additionally, some participants further acknowledged their integration as a state. According to their observations, it appears that three broad aspects involving their integration could be interpreted: work, social-cultural, and psychological aspects as analyzed below.

\section{Work aspects}

In the context of work aspects, the perception of equality, such as the equal treatment with Japanese, was widely perceived as integration. Those who consider themselves as being deprived of equality, such as being excluded from university management, highlighted their failed integration.

There are no foreigners making decisions at any level. That's what frustrates people.

People like me, have permanent residency, permanent positions. But absolutely no, say in any university policy working hours, anything like that (F22).

Dare I say an expert in my field? One of the big frustrations is often I am excluded from decision-making regarding English education. So, I might be in a meeting, and they're going to discuss the program, and they asked me to leave (F26).

In addition, the perception of engagement, displaying as the acceptance and involvement of host institutions, was regarded as integration. Research on integration often finds it difficult to figure out the attitudes of host institutions (Gheorghiu \& Stephens, 2016). Organizational engagement is considered beneficial significantly to the integration of international faculty as it not only contributes to the integration of international faculty practically but also presents hosts' supportive attitudes toward international faculty.

$80 \%$ of the work is in English...publish in English, so I guess most of the inter- 
national faculty can survive...My colleagues and students are very nice, I feel very integrated $(\mathrm{F} 4)$.

I feel like I'm integrated enough...because most of my colleagues are very friendly, open and helpful (F12).

\section{Social-cultural aspects}

Secondly, in social-cultural aspects, similarly, the acquisition of an equal environment was widely viewed as essential for integration. Perceived equality and non-discrimination in the local community was clearly identified as an essential factor required for integration as elaborated below:

For me, integration is just being ordinary...I'm expected to do what other people do and I expect that I will do what other people do. Being given the same rules, being treated fairly and similarly to a Japanese person (F20).

Because people like my neighbor know me as a person, now I'm not the foreigner living next door. I'm X, so I do feel integrated into my neighborhood (F22).

I am quite integrated...So, same as other people, I'm expected by the community to do the same duty (F24).

In addition to equality, relatedness to Japan, including Japanese culture and Japanese people, also appeared as pronounced aspects, which contributes to forming a sense of integration in Japan. Most of the participants agreed that the involvement in Japanese society helped to develop personal networks with Japanese people and inform their knowledge about Japan, which in turn contributed to their involvement with Japan.

I've traveled a lot in Japan. I have been to all forty-seven prefectures...my research has brought me into connection with older generations of Japan...I've traveled around to see them, so that gets me involved in Japan a lot (F13).

A lot of my friends are Japanese, and my coworkers are Japanese. The ones I talk to most are Japanese. My wife is Japanese, our neighbors are Japanese and I'm embedded in Japanese culture (F34).

\section{Psychological aspects}

Finally, in psychological aspects, integration is equated with abstract psychological concepts, such as "home," "comfortable," and "belonging." Those positive expressions are generally associated with "comfort, love and belonging" (Lucas and Purkayastha, 2007:244), which reflected the highest level of their subjective feelings.

It should be something like the people can feel like they are a part of this society, not just like a worker here...It's really belonging to this society to have some feeling of attachment (F1).

I don't feel I am an outsider, I feel like I am at home. I am in the local team, this is comfortable...In Spanish, we say Como Pez en el agua (a fish in the water) (F35). I'm fully integrated...feel comfortable here. Actually, for me, Japan feels more like home now than any other places I have been to in the past 30 years (F37). 


\section{International faculty's intentions of their integration}

Despite the perceived significance and value of integration in Japan, international faculty's intentions of their integration appear to be varied, which can be summarized into three types, namely, separation, one-way adaptation, and two-way adaption.

\subsection{Separation}

Despite a small number, some participants expressed their personal demands of being separated in their workplaces irrespective of the norms and culture of their affiliations. This type of international faculty tends to refuse interactions and prevent integration in Japan. As stressed succinctly:

I am quite happy with this strange situation because I don't like to be a member of things, I like to be alone to be by myself...I'm not joining any group, I don't like it, I like to be isolated (F14).

I am completely detached. I'm separated from the university. So, I live in my own world. I choose to be because I've always been like that (F16).

\subsection{Two-way adaptation}

In contrast, most of the participants highlighted their desire to actively integrate into Japan as in general they were mentally prepared for the perceptual different culture and academic environments when they determined to come to Japan, as claimed below:

I think a lot of foreigners, when they choose to come to Japan they already expecting a different culture, and a lot of them are very open to the idea of learning and living in Japan, integrating into the Japanese culture (F34).

Meanwhile, in addition to their proactive adaptation, many of them emphasized their desires of the efforts and accommodation from their host since they believed that integration should be a two-way process, comprising the mutual adaptation of both international faculty themselves and Japan.

I would say personally, I'm trying my best to learn the culture. Meanwhile, I would prefer an intercultural situation, with openness towards the other...if you hire foreign faculty, then you should offer language, that's part of your work...Do something for it. Don't leave it only to me (F18).

I've been working towards integrating myself into the Japanese culture...But I believe, integration should work both ways...at the same time, I think they need to start changing the way they think they behave (F34).

\subsection{One-way adaptation}

Moreover, many participants expressed their determination to integrate into Japan regardless of the intentions of their affiliations. It seems that participants with Japanese domestic knowledge, such as those from culturally similar countries, and those with previous experiences in Japan, were more prone to this strategy. Their existing knowledge draw from 
their original countries or their subsequent experiences in Japan have largely informed their understanding of Japan, including Japanese language, cultural norms, and university mechanisms, which enabled them more accustomed to Japan.

I got Ph.D. degree from N University, I spent 3 years there as a student. That allowed me to better know the society, to make some friends, to learn the language. I think it made life easier for me...So, I always tried to initiate relationships or cooperation to have a more active role (F1).

I came to Japan in 2010...I got to know much better than before regarding Japanese social culture and interpersonal relationships...whatever happened, as long as I am still here, I will try to integrate with people here (F11).

I can't speak Japanese very well. But since Japanese kanji are very similar to Chinese characters, and many cultures are also very similar, it's not a big problem for me to live here...I'm willing to learn more about Japanese culture as if I am learning ancient Chinese culture (F29).

In summary, regarding the attitudes of international faculty towards their integration in Japan, a majority of the participants agreed that it is a beneficial two-way process in which efforts by both international faculty and Japan should be made. In addition, given the different interpretations of integration, it appears that integration of international faculty in Japan can be characterized as a longstanding process of acquiring equality, developing engagement, and forming a feeling of attachment towards Japan. However, impacted by international faculty's origin of country, previous experience in Japan, and their personal preferences, the data analysis identified three different intentions of international faculty, namely, separation, one-way adaptation, and two-way adaption.

\section{Actual practices of integration}

Regarding the actual practices that international faculty take in integrating into Japan, three categories of actions were identified, namely, preventive, promotional, and occasional, which can be explained by the consistency of international faculty's intentions and their perceived Japan's behaviors towards diverse groups.

\section{Preventive practices}

Firstly, as analyzed previously, when international faculty favor separation in Japan, the rejection of interaction and integration was preferred undoubtedly. Additionally, when the participants perceived their host-Japan is adopting separation approaches, that is, marginalizing international faculty, they tended to embrace preventive strategies. It appears that being a language teacher at Japanese universities makes them more likely to be in this situation. The institutional emphasis on research caused by neoliberalism makes those language teachers more commonly associated with negative experiences, such as a heavier teaching workload, different work roles, and less access to the decision-making process. Thus, the prevention of integration was preferred due to their perceived exclusion, discrimination, and depression.

I've always felt like an outsider...just that lack of respect towards my work...I was very dissatisfied by how the decisions were being made, and I've done as much as I 
can, but very frustrated...I've been thinking maybe I'm going to leave (F26).

The contract Eigokyoushi (English Teachers) have to teach many more classes...So they feel like a member of some different group, like an outsider (F34).

We are just informed about what is going to happen...I try hard to do my best to integrate...but sometimes you cannot be there...You're only one-man army...This system is going to beat you, defeat you eventually (F39).

\section{Promotional practices}

In contrast, when international faculty's intentions reached a consensus with their perceived Japan's behaviors, international faculty were more likely to promote their integration proactively. For example, despite the criticisms of the one-way adaptation in prevailing discourses, when international faculty prefer one-way adaption to their hosts, and their hosts also have the same expectations, positive responses can be predicted. This can be shown from the following quote:

they want us to go for them...I will go to do things with the idea of developing relationships and interact with them...I don't drink...but if the drinking places are the only places they're going to interact with me, I will go and just all drink soda (F30).

The other case is that when the international faculty who preferred two-way adaptation received their institutions' recognition and great support for their integration, they tend to take promotional practices to improve their integration. It seems that Japan's two-way adaptation interactive approaches were particularly likely to be perceived by those who were affiliated in comparatively open academic environments and those who knew the existing frameworks of Japanese universities.

They try their best actually. They put the most important part in English, it's good for me. They are very kind, they want to help me...I take Japan as my country...I take people around me here as kind of family. So, I want and I'm trying to be a part of the society (F19).

The people I work with and our Japanese faculty speak fluent English. If there is an important meeting with foreign faculty, then that meeting is held in English entirely...they helped me translate the important emails, they tried to make it as easy for me as possible. So, I'm also trying my best (F37).

\section{Occasional practices}

Finally, when international faculty's intentions partially differ from their perceived Japan's behaviors, international faculty's actual practices tend to be occasional. For example, when international faculty prefer a mutual adaptation with their hosts, while being expected to be assimilated to local practices, tension caused by this problematic relation may trigger communication breakdown, leading to their disappointment, disillusionment about integration, and distrust of their affiliations. Except for some emphasizing their insistence on integration, most of the participants felt discouraged by this contradiction with their hosts. Under such circumstances, a favorable host environment largely contributes to the integration and retention of international faculty. 
They don't treat us like a diverse department, they treat us as like you have to do this Japanese way, or nothing. So, it's a little disappointing and discouraging...my attitude is kind of apathy. I'm not going to go out of my way or trying to fight too hard with anything (F13).

However, some stated that their actions could change if their hosts decide to take their intentions and desires into consideration, implying that integration and trust can be formed conditionally (Tierney, 2008). The condition is a favorable environment where they can be well respected and involved. Under such circumstances, the hosts should be more accountable.

I have sort of a bad attitude...Now I don't care very much...unless they're going to show me that they value my opinion and want me really to be a part of the system, I would change my mind. I would absolutely go for it (F22).

I think probably I will remain an outsider...But it depends on what happens. If they give me an opportunity to do something like, okay, we want you to be in charge of there, maybe I'll stay (F26).

As analyzed above, international faculty's perceptions of their hosts seem to be varied by their work roles (language teaching), and the overall environment of their hosts. Drawing on the consistency of international faculty's intentions and their perceived Japan's behaviors towards them, three broad practical behaviors towards integration were summarized as shown in Table 2. The data analysis indicates that when international faculty's intentions and their perceptions of Japan's behaviors are separation, international faculty were more likely to disfavor integration. In contrast, when their intentions and their perceptions of Japan's behaviors reached consensual interactive relations, international faculty tend to promote their integration proactively. Finally, when international faculty's intentions and perceptions on Japan's behaviors experience partial agreement and partial disagreement, they tend to show occasional behavior varied by individuals.

\section{Discussion and conclusions}

By focusing on international faculty's attitudes and actual practices towards their integration in Japan, the study yielded two key findings. Firstly, a majority of international faculty perceived their integration as a beneficial longstanding two-way process of acquiring equality, developing engagement, and forming a feeling of attachment towards Japan. Secondly, despite the perceived benefits and value, their actual practices towards integration appear to be diverse, including three broad categories: preventive, occasional, and promotional. These two findings are discussed in detail subsequently.

Table 2 International faculty's actual practices of integration

\begin{tabular}{llll}
\hline Perceived Japan's behaviors & \multicolumn{2}{l}{ International faculty's intentions } & \\
\cline { 2 - 4 } & Two-way adaptation & One-way adaptation & Separation \\
\hline Two-way adaptation & Promotional & Occasional & Preventive \\
One-way adaptation & Occasional & Promotional & Preventive \\
Separation & Preventive & Preventive & Preventive \\
\hline
\end{tabular}


Firstly, the study suggests that international faculty view their integration in Japan as both a process and state. On the one hand, integration as a two-way process is consistent with the generally accepted notions in migration studies (e.g., Korteweg, 2017). On the other hand, the integration proposed as a state is opposed to the notion of being a process. Despite the contradiction, the mutually reinforcing relationship between process and state should be noted. Without process, states of integration can hardly be achieved. Vice versa, the states of integration contribute to the further integration process. Additionally, depending on the individuals, their intentions of integration vary. This echoes Castles et al. (2001), remarking on multiple individual modes of integration. Therefore, the study has complemented the existent integration discourses by providing international faculty's voices in Japan.

Secondly, the analysis indicates variations in their actual practices regarding their integration in Japan. On the one hand, the analysis emphasizes the differences in the actual integration practices between international faculty primarily engaged in research and those associated with teaching activities. The facts that most of the language teachers were from Western countries with huge cultural dissimilarities, and that few of them have previous experience in Japan as most of them didn't graduate from Japanese universities (Huang, 2018a), have made their integration more ambiguous. This is a disadvantageous situation where organizational support is urgently needed. However, instead of sufficient facilitation, Japanese universities have striven to improve efficiency by maximizing the productivity of research faculty and imposing excessive teaching loads on language teachers. Despite a strong desire to advance their scholarly reputation, the tensions caused by professional and social-cultural constraints leave them struggling to meet the minimum requirements for promotion, resulting in their fewer professional opportunities (Huang et al., 2019). Consequently, they are more likely to be confined to peripheral roles (Nishikawa, 2021). This is maybe why they tend to prevent integration and create their own private spaces to protect themselves.

On the other hand, the study suggests that the research faculty who were from similar cultural backgrounds or had previous experience in Japan tend to proactively promote their integration. This is possibly because the experiences related to Japan help to inform their Japanese knowledge, which is conducive to better integration. This may explain why Chinese/Korean faculty encounter fewer challenges (Huang et al., 2019), and higher-ranked international faculty tend to be educated in Japan (Huang, 2018a). In addition, due to the vigorous promotion of the Nihonjinron ideology by the Japanese government (Morita, 2017), highlighting Japanese uniqueness of culture and values, international faculty who have better Japanese local knowledge, including Japanese language and culture, tend to be highly valued, supported by the fact that those who are familiar with Japanese culture and management are preferred even though some of them may be underqualified (Maki et al., 2015; Nishikawa, 2021). Thus, a better knowledge of Japan, which can be informed by origin and previous experience in Japan, was found to contribute to a higher level of integration significantly since it helps international faculty not only to integrate into Japan individually but also to illuminate their value in Japan institutionally. Therefore, those who have a better Japanese knowledge were more willing to integrate into Japan, and they were also the kind of faculty that Japan would like to integrate.

Thirdly, the study indicates a disjunction between international faculty's attitudes and their actual practices of integration in Japan as despite their positive attitudes, many participants prevented integration. This can be attributed to the characteristics of both international faculty and host environment, which were influenced by perceived Japan's behavior from a macro perspective, work role from a meso perspective, and personal intention, 
origin of country, and previous experience in Japan from a micro perspective. Intrinsically, echoing Schinkel (2018), the findings suggest that the extent to which integration is a critical issue for international faculty should be noted. In other words, more integrated does not necessarily equal more harmonious in Japan as personal intention of integration was recognized as an essential factor.

More importantly, the study underscores the great influences of Japan's overall host environment, as the institutional practices enabled those extrinsic factors, such as work roles, to impact significantly the integration of international faculty. This is consistent with existing evidence suggesting the decisive impacts of hosts (e.g., Penninx, 2019). Despite being characterized as similar to other universities in East Asian countries, following western practices to develop a global framework through hiring international faculty (Shun Wing Ng, 2012), the current situation of Japan's HE system is heavily influenced by its institutional practices. Forced by external neoliberal-framed globalization, Japanese universities were required to be responsible for the cultivation of global human resources, who can contribute to the revitalization of the Japanese economy (Ota, 2018). Meanwhile, caused by the relative decline of the annual national operational funding from the Japanese government, the internationalization of Japanese HEIs has become a means to gain extra funding as the initiatives for internationalization always bring a significant amount of funding.

Spurred by external neoliberalism and internal internationalization as outlined, Japanese HEIs were compelled to strive for both excellence and diversity. Under such a circumstance, the recruitment of diversified highly skilled scholars is particularly urgent. However, given the fact that scientific excellence has been acknowledged as a significant incentive for international faculty in Japan (Huang, 2018a; Yonezawa et al., 2014), the relative decline of research prestige and excellence in Japan is detrimental to the recruitment of such talents, as pointed out by Rappleye and Vickers (2015). Therefore, the Japanese academic system has adopted a self-contained system, implying retaining international faculty who were graduated from Japanese universities to improve Japanese scientific excellence, reinforced by existing evidence indicating that most of the international faculty engaged in research activities were graduate students of Japanese universities (Huang, 2018a; Yonezawa et al., 2014). On the other hand, in order to meet the demand for diversity, Japanese universities were compelled to lower their employment requirements, such as not requiring Ph.D. degrees, to hire international faculty from a wider range of countries. Thus, many international faculty, who were not Ph.D. holders, were hired by Japanese universities, especially those from western countries.

Therefore, Japan has addressed the "disparity" - diversity through integrating international contents and perspectives, and excellence driven by the neoliberal-framed academic market (Kim, 2009:48) — separately in practice. In other words, those who are mainly associated with teaching activities, especially the native language teachers, were expected to contribute more to diversity. Whereas, research faculty were considered as agents to promote excellence and the world-class status of Japanese universities. This seems largely different from other East Asian countries. For example, provided with sufficient funding initiatives, Chinese universities strive for the "world-leading experts" with study/work experiences abroad to enhance research capabilities (Wu \& Huang, 2018; Mok and Marginson, 2021). In contrast, international faculty at South Korean universities are expected to teach, develop international networks, and participate in social contributions rather than research (Shin \& Gress, 2018). Therefore, the practical milieus of Japanese HEIs have led to the complexity of international faculty at Japanese universities, resulting in their comparatively diverse actual practices of integration. 


\section{Implications and limitations}

As for implications, firstly, given the value of integration, the coordination of comprehensive policies covering both recruitment and integration of international faculty is greatly needed. Secondly, the research findings help to provide empirical evidence for further relevant research and to extend the limited myriad contributions of international faculty in HEIs, not just in Asia but also other non-colonial, non-English-speaking countries outside of Asia that have actively recruited international faculty. Thirdly, more proactive initiatives are expected to be undertaken by Japan to create a more favorable and accommodating host environment and find a pathway forward to the integration of international perspectives.

Regarding the limitations, firstly, the study investigated the intentions of the hostJapan from international faculty's narratives indirectly, further studies are needed to explore Japan's specific perceptions directly. Secondly, given the variations in their attitudes, investigations into the mechanisms of how different attitudes lead to various kinds of integration are necessary. Finally, it's obviously unclear whether and to what extent the study can be generalized to other international faculty in the context of other countries, and this could be a potentially fruitful area for future research.

Acknowledgements The author would like to express her enormous gratitude to Professor Futao Huang for the kind support and to Dr. Howell Peter Kenneth for proofreading this article.

Author contribution Not applicable.

Data availability Not applicable.

Code availability Not applicable.

\section{Declarations}

Conflict of interest The authors declare no competing interests.

\section{References}

Alba, R., \& Nee, V. (1997). Rethinking Assimilation Theory for a New Era of Immigration. International Migration Review, 31(4), 826-874.

Argyris, C. (1976). Leadership, learning and changing the status quo. Organizational Dynamics, 4(3), 29-43.

Argyris, C., \& Schön, D. A. (1974) Theory in practice. Increasing professional effectivenessJossey-Bass Publishers

Argyris, C., Putman, R., \& Smith, D. M. (1987). Action science. Concepts, methods, and skills for research and intervention. California: Jossey-Bass Publishers.

Brotherhood, T., Hammond, C. D., \& Kim, Y. (2020). Towards an actor-centered typology of internationalization: A study of junior international faculty in Japanese universities. Higher Education, 79, 497-514. https://doi.org/10.1007/s10734-019-00420-5

CAPOBIANCO, P. (2017). < Research Note>Bridging the Gap between Japanese and Foreign Communities through Communication and Critical Reflection. https://doi.org/10.15068/00146787

Castles, S., Korac, M., Vasta, E. and Vertovec, S. (2001/2002). Integration: Mapping the Field. Home Office Online Report 29/03. London: Home Office Online Report 28/03: http://webarchive.natio nalarchives.gov.uk/20110218135832/http://rds.homeoffice.gov.uk/rds/pdfs2/rdsolr2803.doc.

Collins, J. M. (2008). Coming to America: Challenges for faculty coming to United States' universities. Journal of Geography in Higher Education, 32(2), 179-188. 
Corley, E. A., \& Sabharwal, M. (2007). Foreign-born academic scientists and engineers: Producing more and getting less than their U.S.-born peers? Research in Higher Education, 48(8), 909-941.

Froese, F. (2010). Acculturation experiences in Korea and Japan. Culture \& Psychology, 16(3), 333-348. https://doi.org/10.1177/1354067X10371138

Froese, F. (2012). Motivation and adjustment of self-initiated expatriates: The case of expatriate academics in South Korea. The International Journal of Human Resource Management, 23(6), 1095-1112. https://doi.org/10.1080/09585192.2011.561220

Gahungu, A. (2011). Integration of foreign-born faculty in academia: Foreignness as an asset. Int. J. Educ. Leadership Prep, 6(1), 1-22.

Gheorghiu, E., \& Stephens, C.S. (2016). Working with “The Others": Immigrant academics' acculturation strategies as determinants of perceptions of conflict at work. The Social Science Journal, https://doi. org/10.1016/j.soscij.2016.08.002

Gress, D. R. \& Shin, J. (2020). Perceptual differences between expatriate faculty and senior managers regarding acculturation at a Korean university, The Social Science Journal, DOI: https://doi.org/10. $1080 / 03623319.2020 .1813863$

Huang, F. (2018a). International faculty at Japanese universities: Their demographic characteristics and work roles. Asia Pacific Education Review, 19(2), 263-272.

Huang, F. (2018b). International faculty at Japanese universities: Profiles and motivations. Higher Education Quarterly, 72(3), 237-249.

Huang, F. \& Chen, L. (2021). Chinese Faculty Members at Japanese Universities: Who Are They and Why Do They Work in Japan? ECNU Review of Education, https://doi.org/10.1177/2096531120985877

Huang, F. \& Daizen, T. (2020). Gaikokujinkyouin nikansuru kokusaihikakuteki kenkyu [International Comparative Study on international faculty]. Reviews in Higher Education, 154.

Huang, F., Daizen, T.\&Kim, Y. (2019). Challenges facing international faculty at Japanese universities: Main findings from the 2017 national survey. International Journal of Educational Development, https://doi.org/10.1016/j.ijedudev.2019.102103

Jiang, X., Napoli, R. D., Borg, M., Maunder, R., Fry, H., \& Walsh, E. (2010). Becoming and being an academic: The perspectives of Chinese staff in two research-intensive UK universities. Studies in Higher Education, 3(2), 155-170. https://doi.org/10.1080/03075070902995213

Jonasson, C., Lauring, J., Selmer, J., \& Trembath, J. L. (2017). Job resources and demands for expatriate academics: Linking teacher-student relations, intercultural adjustment, and job satisfaction. Journal of Global Mobility, 5, 5-21.

Kim, T. (2009). Transnational academic mobility, internationalization and interculturality in higher education. Intercultural Education, 20(5), 395-405.

Kim, S. (2016). Western faculty 'flight risk' at a Korean university and the complexities of internationalisation in Asian higher education. Comparative Education, 52(1), 78-90. https://doi.org/10.1080/03050 068.2015.1125620

Kim, K. M. (2018). Academic socialization of doctoral students through feedback networks: A qualitative understanding of the graduate feedback landscape. Teaching in Higher Education, 23(8), 963-980.

Korteweg, A. C. (2017). The Failures of "Immigrant Integration": The Gendered Racialized Production of Non-Belonging. Migration Studies, 5(3), 428-444.

Lucas, S., \& Purkayastha, B. (2007). Where Is Home? Here and There: Transnational Experiences of Home Among Canadian Migrants in the United States. GeoJournal, 68(2-3), 243-251.

Maki, M., Ebisuya, A., \& Sekiguchi, T. (2015). Nihon kigyo honsha ni okeru jinji kokusaika no gengo to kadai [The internationalization of human resource practices in Japanese headquarters.]. Multinational Enterprises, 8(1), 93-113.

McClure, J. W. (2007). International graduates' cross-cultural adjustment: Experiences, copingstrategies, and suggested programmatic responses. Teaching in Higher Education, 12(2), 199-217.

McNeill, D. (2007). Still foreign after all these years. The Chronicle of Higher Education, 53(24). Available at: http://chronicle.com/article/Still-Foreign-After-All-These/34523.

MEXT. (2020). https://www.e-stat.go.jp/stat-search/files?page $=1 \&$ layout=datalist\&toukei $=00400001 \&$ tstat $=000001011528 \&$ cycle $=0 \&$ tclass $1=000001135783 \&$ tclass $2=000001135810 \&$ tclass $3=00000$ $1135811 \&$ tclass4 $=000001135813$.

Mok, K.H. and Marginson, S. (2021). Massification, diversification and internationalisation of higher education in China: Critical reflections of developments in the last two decades. International Journal of Educational Development. https://doi.org/10.1016/j.ijedudev.2021.102405

Morita, L. (2017). Why Japan isn't more attractive to highly-skilled migrants. Cogent Social Sciences, $3(1306952), 1-12$.

Nishikawa, Thomas. (2021). The Internationalization of Japanese Universities: A Case Study on the Integration of Foreign Faculty. https://doi.org/10.17638/03118952 
O'Keefe, G. J. (2017). The typological hybrid identity formation of long-term western foreign residents in Japan. https://doi.org/10.15017/1866241

O’Meara, K. (2014). Half-way out: How requiring outside offers to raise salaries influences faculty retention and organizational commitment. Research in Higher Education, 55(4), 1-22.

Oishi, N. (2020): Skilled or unskilled?: The reconfiguration of migration policies in Japan, Journal of Ethnic and Migration Studies, DOI: https://doi.org/10.1080/1369183X.2020.1731984

O'Neill, M. (2014). The Slow University: Work, Time and Well-Being. Forum: Qualitative Social Research. 14. ISSN $1438-5627$

Ota, H. (2018). Internationalization of Higher Education: Global Trends and Japan's Challenges. Educational Studies in Japan, 12, 91-105. https://doi.org/10.7571/esjkyoiku.12.91

Penninx, R. (2019). Problems of and solutions for the study of Immigrant Integration. Comparative Migration Studies, 7. https://doi.org/10.1186/s40878-019-0122-x

Rappleye J. and Vickers, E. (2015). Can Japanese universities really become Super Global? University World News. http://www.universityworldnews.com/article.php?story=20151103154757426

Rogers, L., Ottman, E., \& Pavloska, S. (2020). Hidden Biases and Their Influences on Multiple Oppressions Experienced by Non-Japanese Residents in Japan. https://doi.org/10.15020/00001894

Schinkel, W. (2018). Against 'immigrant integration': for an end to neocolonial knowledge production. Comparative Migration Studies, https://doi.org/10.1186/s40878-018-0095-1

Selmer, J., \& Lauring, J. (2011). Expatriate academics: Job factors and work outcomes. International Journal of Manpower, 32, 194-210.

Shin, J. C., \& Gress, D. R. (2018). Expatriate academics and managing diversity: A Korean host university's perspective. Asia Pacific Educ. Rev., 19, 297-306. https://doi.org/10.1007/s12564-018-9539-4

Shun Wing Ng. (2012). Rethinking the mission of internationalization of higher education in the AsiaPacific region, Compare: A Journal of Comparative and International Education, 42:3, 439-459, DOI: https://doi.org/10.1080/03057925.2011.652815

Ager \& Strang. (2008). Understanding Integration: A conceptual Framework. Journal of Refugee Studies, 21, 2. Published by Oxford University Press. 166-191. doi:https://doi.org/10.1093/jrs/fen016

Teichler, U. (2017). Internationally Mobile Academics Concept and Findings in Europe. European Journal of Higher Education, 7, 15-28.

Tierney, W. G. (2008). Trust and organizational culture in higher education. J. Valimma \& O.H. Ylijoke Eds., Cultural perspectives on higher education. Chapter 3 (27-41). Springer.

van der Wende, M. (2015). International academic mobility Towards a concentration of the minds in Europe. European Review, 23(1), 70-88. https://doi.org/10.1017/S1062798714000799

Wang, J., Hooi, R., Li, A., \& X Chou M. (2019). Collaboration patterns of mobile academics The impact of international mobility. Science and Public Policy, 46(3), 450-462.

Wilkins, S., \& Neri, S. (2019). Managing Faculty in Transnational Higher Education Expatriate Academics at International Branch Campuses. Journal of Studies in International Education, 23(4), 451-472.

Wu, X., \& Huang, F. (2018). International faculty in China: Case studies of four leading universities in Shanghai. Asia Pacific Education Review, 19(2), 253-262. https://doi.org/10.1007/s12564-018-9535-8

Yonezawa A., Ishida K. and Horta H. (2014). The long-term internationalization of higher education in Japan: A survey of non-Japanese faculty members in Japanese universities. in E.G. Mok, K. and Yu, K. (Eds). Internationalization of higher education in East Asia : trends of student mobility and impact on education governance (176-188). Routledge.

Yudkevich, M., Altbach, P.G., Rumbley, L.E. (Eds.). (2017). International faculty in Higher Education: Comparative Perspectives on Recruitment, Integration, and Impact. Routledge.

Zhou, M. (1997). Segmented Assimilation: Issues Controversies, and Recent Research on the New Second Generation. International Migration Review, 31(4), 975-1008.

Publisher's Note Springer Nature remains neutral with regard to jurisdictional claims in published maps and institutional affiliations. 